\title{
Adenosine Triphosphate-Binding Cassette Subfamily C Member 2 Is the Major Transporter of the Hepatobiliary Imaging Agent ${ }^{99 m}$ Tc-Mebrofenin
}

Kuldeep K. Bhargava ${ }^{1}$, Brigid Joseph ${ }^{2}$, Meenakshisundaram Ananthanarayanan ${ }^{3}$, Natarajan Balasubramaniyan ${ }^{3}$, Gene G. Tronco ${ }^{1}$, Christopher J. Palestro ${ }^{1}$, and Sanjeev Gupta ${ }^{2}$

${ }^{I}$ Division of Nuclear Medicine and Molecular Imaging, North Shore-Long Island Health System, New Hyde Park, New York and Albert Einstein College of Medicine, Bronx, New York; ${ }^{2}$ Departments of Medicine and Pathology, Marion Bessin Liver Research Center, Cancer Research Center, Diabetes Center and Institute for Clinical and Translational Research, Jack and Pearl Resnick Campus, Albert Einstein College of Medicine, Bronx, New York; and ${ }^{3}$ Department of Pediatrics, Mount Sinai School of Medicine, New York, New York

The organic anion $99 \mathrm{mTc}-\mathrm{N}-[2-[(3-$ bromo-2,4,6-trimethylphenyl)amino]-2-oxoethyl]- $N$-(carboxymethyl)-glycine ( ${ }^{99 m}$ Tc-mebrofenin) and its analogs are widely used for hepatobiliary imaging. Identification of the mechanisms directing bile canalicular transport of these agents will provide insights into the basis of their hepatic handling for assessing perturbations. Methods: We performed studies in animals, including healthy Fischer 344 rats or rats treated with carbon tetrachloride or intrasplenic cell transplantation and healthy Wistar rats or HsdAMC:TR-Abcc2 mutant rats in Wistar background. Onset of hepatic inflammation was verified by analysis of carbon uptake in Kupffer cells. Hepatic clearance of 99mTc-mebrofenin was studied with dynamic imaging, and fractional retention of peak hepatic mebrofenin activity after 60 min was determined. Changes in the expression of bile canalicular transporters were analyzed by real-time polymerase chain reaction and Western blots. Results: Carbon tetrachloride and cell transplantation produced hepatic inflammation with activation of Kupffer cells, resulting in a rapid decline in the expression of the bile canalicular transporters $A b c b 4, A b c b 11$, and Abcc2. Among these transporters, decreased expression of $A b c c 2$ was most prominent, and this decline persisted for $4 \mathrm{wk}$. Next, we examined 99mTc-mebrofenin excretion in HsdAMC:TR-Abcc2 mutant rats (in which $A b c c 2$ expression is naturally inactivated), compared with their healthy counterparts. In healthy HsdRccHan:WIST rats, only $23 \% \pm 3 \%$ of the peak $99 \mathrm{mTc}$-mebrofenin activity was retained after $60 \mathrm{~min}$. By contrast, in HsdAMC:TR-Abcc2 mutant rats, $73 \% \pm 5 \%$ of the peak ${ }^{99 m}$ Tc-mebrofenin activity was retained $(P<0.001)$. Moreover, the administration of cyclosporin A markedly inhibited ${ }^{99 m}$ Tc-mebrofenin excretion in healthy rats, with no further effect on already impaired ${ }^{99 m T c-m e b r o f e n i n ~ e x-~}$ cretion in HsdAMC:TR-Abcc2 mutant rats. Hepatic excretion of 99mTc-mebrofenin was largely dependent on Abcc2. This molecular basis of ${ }^{99 \mathrm{mT}} \mathrm{T}$-mebrofenin excretion will advance studies of pathophysiologic mechanisms in hepatic Abcc2 pathways.

Received Jan. 21, 2009; revision accepted Mar. 16, 2009.

For correspondence or reprints contact: Sanjeev Gupta, Albert Einstein College of Medicine, Ullmann Bldg., Room 625, 1300 Morris Park Ave.,

Bronx, NY 10461.

E-mail: sanjvgupta@pol.net

COPYRIGHT @ 2009 by the Society of Nuclear Medicine, Inc.
Key Words: canalicular; gene; liver; 99mTc-mebrofenin; transport

J Nucl Med 2009; 50:1140-1146

DOI: 10.2967/jnumed.109.062448

\section{$\mathbf{T}$} he imaging agent $N$-[2-[(3-bromo-2,4,6-trimethylphenyl)-amino]-2-oxoethyl]- $N$-(carboxymethyl)-glycine conjugated to technetium $\left({ }^{99 \mathrm{~m}} \mathrm{Tc}-\mathrm{mebrofenin}\right)$ and related compounds are extensively used for diagnosing cholestasis, gallbladder function, and bile leaks (1). The avidity of these compounds for hepatocytes $(>80 \%$ of intravenously administered ${ }^{99 \mathrm{~m}} \mathrm{Tc}$-mebrofenin is cleared from blood within $10 \mathrm{~min}$, with incorporation essentially in the liver, followed by rapid excretion in bile) has been highly attractive for imaging applications (2). The mechanism by which ${ }^{99 \mathrm{~m}} \mathrm{Tc}-$ mebrofenin enters hepatocytes is unknown, although as an organic anion, basolateral transporters (e.g., members of the solute carrier family [SLC]-SLCO1B1, SLCO1B3, and possibly others) may be involved $(3,4)$. Subsequently, 99mTc-mebrofenin exits hepatocytes without metabolism or modifications to enter the bile canaliculus; however, the transport mechanism by which this exit is accomplished has been unknown. Many bile canalicular transporters have been identified to date, many belonging to adenosine triphosphate (ATP)-binding cassette (ABC) subfamilies, and their properties have been extensively studied because these transporters serve major roles in health and disease, including the characterization of the genetics, molecular and biochemical activities, and phenotypic effects of specific mutations in several instances (5-7).

Recently, we found that inflammatory cytokines-tumor necrosis factor (TNF)- $\alpha$ and interleukin-6-blocked hepatobiliary transport of ${ }^{99 \mathrm{~m}} \mathrm{Tc}$-mebrofenin $(8,9)$. In this way, 
hepatic excretion of ${ }^{99 \mathrm{~m}} \mathrm{Tc}-\mathrm{mebrofenin}$ offered an intracellular reporter pathway for assaying activation of inflammatory cells, induced experimentally either by the administration of the hepatotoxin carbon tetrachloride $\left(\mathrm{CCl}_{4}\right)$ or by the transplantation of cells in the liver. Rapid and persistent inhibition of ${ }^{99 \mathrm{~m}} \mathrm{Tc}$-mebrofenin excretion, becoming abnormal immediately after the onset of inflammation and remaining abnormal during persistent inflammation under these conditions, indicated that the identification of specific cellular mechanisms responsible for transporting ${ }^{99 \mathrm{~m}} \mathrm{Tc}-\mathrm{mebrofenin}$ into bile will be significant for various applications. Here, we report studies that led us to the $\mathrm{ABC}$ subfamily $\mathrm{C}$ member 2 ( $A b c c 2)$-which mediates the secretion of amphiphilic glutathione, glucuronide, and sulfate conjugates into bile $(5,10)$-as the major relevant bile canalicular transporter of ${ }^{99 \mathrm{~m}} \mathrm{Tc}-\mathrm{mebro}-$ fenin. We performed these studies in well-defined rat models, syngeneic animals deficient in dipeptidyl peptidase IV (DPPIV) enzyme activity to serve as recipients for localizing healthy DPPIV-positive transplanted cells (9), animals with $\mathrm{CCl}_{4}$-induced liver injury (8), and animals mutant in the $A b c c 2$ gene (11), which is also known as multidrug resistance protein-2.

\section{MATERIALS AND METHODS}

\section{Animals and Surgical Procedures}

A total of 40 DPPIV-negative (DPPIV-) Fischer 344 (F344) rats were studied. These animals were 6-8 wk old, weighed 120$180 \mathrm{~g}$, and were provided by the Special Animal Core of Marion Bessin Liver Research Center. Healthy F344 rats were from the National Cancer Institute. HsdAmc:TR-Abcc2 mutant rats in Wistar background and their healthy counterparts, HsdRccHan: WIST rats, were from Harlan. Animal Care and Use Committees for Albert Einstein College of Medicine and Long Island Jewish Medical Center approved the experimental protocols.

For surgery, rats were anesthetized with ketamine and xylazine (Fort Dodge Animal Health). Hepatocytes were isolated from F344 rats by standard 2-step collagenase perfusion of the liver. Cell viability was examined using trypan blue dye exclusion. In DPPIVrats, $2 \times 10^{7}$ hepatocytes were injected over 9-12 s via the splenic pulp $(9,12)$. To induce chemical liver injury, $\mathrm{CCl}_{4}$ was administered intramuscularly to DPPIV - rats. Animals were sacrificed at $6 \mathrm{~h}, 1 \mathrm{~d}$, or $3 \mathrm{~d}$ or at $1,2,3$, and $4 \mathrm{wk}$ after cell transplantation or $\mathrm{CCl}_{4}$ treatment ( $n=3$ each). Carbon was administered 60 min before sacrifice to demonstrate Kupffer cell activation, as described previously (12). A 10 or $15 \mathrm{mg} / \mathrm{kg}$ dose of cyclosporin A was given by gavage $2-3 \mathrm{~h}$ before ${ }^{99 \mathrm{~m}} \mathrm{Tc}-\mathrm{mebrofenin}$ studies to some HsdAmc:TR-Abcc2 and F344 rats ( $n=6$ each) (13).

\section{Drugs and Chemicals}

$\mathrm{CCl}_{4}$, cyclosporin $\mathrm{A}$, mineral oil, and chemicals were purchased commercially (Sigma Chemical Co.). $\mathrm{CCl}_{4}$ was suspended in mineral oil $(1: 1, \mathrm{v} / \mathrm{v})$, and cyclosporin $\mathrm{A}$ was solubilized in ethanol. A kit was used for preparing ${ }^{99 \mathrm{~m}} \mathrm{Tc}-\mathrm{mebrofenin}$ (Choletec; Bracco Diagnostics).

\section{9mTc-Mebrofenin Imaging}

Commercially available mebrofenin was mixed with ${ }^{99 m} \mathrm{Tc}-$ sodium pertechnetate $(185-222 \mathrm{MBq})$ in $3 \mathrm{~mL}$ of normal saline.
This solution was diluted in normal saline and then mixed with ${ }^{99 \mathrm{~m}} \mathrm{Tc}$-mebrofenin $(7.4 \mathrm{MBq})$, and $1 \mathrm{~mL}$ was injected into the splenic pulp. Beginning immediately after the injection of ${ }^{99 \mathrm{~m}} \mathrm{Tc}-$ mebrofenin, 10-s dorsal images were acquired for 60 min with a $\gamma$-camera (Argus; ADAC Laboratories) (8). Data were analyzed on a commercially available nuclear medicine workstation by drawing regions of interest over the liver and generating timeactivity curves. The time to maximal accumulation of ${ }^{99 \mathrm{~m}} \mathrm{Tc}-$ mebrofenin, Tpeak, and percentage of Tpeak ${ }^{99 \mathrm{~m} T c-m e b r o f e n i n}$ activity remaining at $60 \mathrm{~min}$ after injection were determined.

\section{Reverse-Transcription Polymerase Chain Reaction (RT-PCR)}

Total RNA was isolated with TRIzol (Invitrogen Corp.) and treated with RNase-free DNase (Qiagen Inc.), and cDNA was prepared from 2-4 $\mu \mathrm{g}$ of RNA with an Omniscript RT Kit (Qiagen). TNF- $\alpha$, macrophage inflammatory protein-2, monocyte chemotactic protein-1, and interferon-inducible protein-10 were analyzed by semiquantitative RT-PCR, as described previously (14). Real-time quantitative PCR (qPCR) was performed with commercially available primers for rat TNF- $\alpha$ and $\beta$-actin (MGC124630, reference sequence NM012675; and PRR06570B, reference sequence NM031144, respectively; SA Biosciences). After DNase treatment, $1 \mu \mathrm{g}$ of total RNA was converted to cDNA with a RT ${ }^{2}$ PCR Array First Strand Kit (SA Biosciences). Realtime PCR was performed with a RT $^{2}$ Real-Time SYBR Green PCR Master Mix (SA Biosciences), according to the manufacturer's instructions, in an ABI Prism 7000 Sequence Detection System (Applied Biosystems). PCR products were analyzed in 2\% agarose gels with ethidium bromide to verify single products. Fold changes in gene expression were calculated on the basis of PCR cycle threshold $(\mathrm{Ct})$ values between experimental and control samples after normalizing data in each sample with $\beta$-actin. Realtime qPCR for biliary transporters used a Brilliant SYBR GreenQPCR kit from Qiagen. Briefly, $5 \mu \mathrm{g}$ of total RNAs were reverse-transcribed with Superscript II (GIBCO-BRL). Primers were designed to generate 150-base pair amplicons (Table 1). PCR was performed in a PRISM 7900HT system (Applied Biosystems Inc.), with 1 cycle for $15 \mathrm{~min}$ at $95^{\circ} \mathrm{C}$ and 40 cycles at $94^{\circ} \mathrm{C}$ for $15 \mathrm{~s}, 55^{\circ} \mathrm{C}$ for $30 \mathrm{~s}$, and $72^{\circ} \mathrm{C}$ for $30 \mathrm{~s}$. Product sizes were verified in $2 \%$ agarose gels. Data were analyzed by software (SDS, version 2.1; Applied Biosystems Inc.) to obtain Ct values. $\mathrm{Ct}$ values for 18S RNA served as a denominator for normalization. Gene expression was expressed as fold change above controls.

\section{Tissue Studies}

Liver samples were cooled to $-80^{\circ} \mathrm{C}$ in methylbutane or fixed in $10 \%$ buffered formalin. Paraffin-embedded tissue sections were stained with hematoxylin and eosin according to standard methods. To visualize transplanted cells, 5 - $\mu$ m-thick cryosections were prepared and stained histochemically for DPPIV, as described previously (12). Incorporation of carbon in Kupffer cells was also analyzed as described previously (12). The number of Kupffer cells with carbon was counted in 50 consecutive highpower fields per tissue $(n=3-4$ rats, each under $\times 200$ magnification with centering on portal areas).

\section{Western Blot Analysis}

Tissue samples weighing $100 \mathrm{mg}$ were homogenized in $1 \mathrm{~mL}$ of $1 \mathrm{mM}$ sodium bicarbonate with protease inhibitors; the clear supernatant was incubated with $100 \mathrm{mM}$ sodium bicarbonate with protease inhibitors for $15 \mathrm{~min}$, followed by centrifugation under 
TABLE 1. qPCR Primers for Bile Canalicular Transporters

\begin{tabular}{|c|c|c|c|}
\hline Gene $^{*}$ & Accession no. & Orientation & Primer sequence, $5^{\prime}-3^{\prime}$ \\
\hline \multirow[t]{2}{*}{ Abcb4 (Mdr2/3) } & NM_012690 & Forward & AAAAAACACGGACCTTACAGGAA \\
\hline & & Reverse & CTACATGAATGCTTGTGAGATGCT \\
\hline \multirow[t]{2}{*}{ Abcb11 (Bsep) } & NM_031760 & Forward & CAGGCGGAGGCAAGTCTTC \\
\hline & & Reverse & CCСАTCACAACGTCATCTTGA \\
\hline \multirow[t]{2}{*}{ Abcc2 (Mrp2) } & NM_01283 & Forward & CTGGAGTTGGCTCACCTCAGAT \\
\hline & & Reverse & CTCTGCCCTATGCTCAGGTTGT \\
\hline \multirow[t]{2}{*}{ Abcg2 (Bcrp) } & NM_181381 & Forward & AGGGCCGGACCATCATCT \\
\hline & & Reverse & CAGTAAGGTGAGGCTGTCAAACA \\
\hline *Altern & ses. & & \\
\hline
\end{tabular}

$100,000 \mathrm{~g}$ for $1 \mathrm{~h}$ at $4^{\circ} \mathrm{C}$. The pellet was resuspended in water and disrupted by ultrasonication. Bradford reagent was used for measuring protein content, and equal amounts of protein were resolved in $10 \%$ sodium dodecyl-polyacrylamide gels to prepare transblots with standard methods. Transblots were probed with antibodies (dilution, 1:1,000) in phosphate-buffered saline against Abcb11 (PC-064, Kamiya Biomedical Co.), Abcc2 (Gene Tex Inc.), and solute carrier (SLC) organic anion transporter family member 1B1 (Slcolb1) (from Allan Wolkoff, Albert Einstein College of Medicine). Antibody binding was demonstrated with 1:5,000 dilutions in phosphate-buffered saline of peroxidaseconjugated antirabbit IgG for Abcb11 and Slcolb1 (NA934W; GE Healthcare U.K. Ltd.) or antimouse IgG for Abcc2 (A3673; Sigma), followed by detection with enzymatic chemiluminescence (NEL104; Perkin Elmer LAS Inc.). Blots were reprobed after regeneration with Restore Western Blot Stripping Buffer (Pierce Biotechnology Inc.).

\section{Blood Tests}

Serum was stored at $-20^{\circ} \mathrm{C}$ for total bilirubin, alanine aminotransferase, and alkaline phosphatase measurements with an automated clinical system.

\section{Statistical Analysis}

Data are shown as mean \pm SEM. Significances were analyzed by SigmaStat 3.0 software (Jandel Scientific) with the $t$ test, Mann-Whitney rank sum test, or ANOVA with the Holm-Sidak method, as appropriate. A $P$ value of less than 0.05 was considered significant.

\section{RESULTS}

\section{Evidence for Inflammation After Cell Transplantation and $\mathrm{CCl}_{4}$ Treatment}

In DPPIV - rats, transplanted cells were identified in the liver, and hepatic morphology was normal throughout the studies. In animals treated with $\mathrm{CCl}_{4}$, liver necrosis was observed after $1 \mathrm{~d}$, whereas liver morphology was normal at subsequent times. Kupffer cells were activated with carbon incorporation after $\mathrm{CCl}_{4}$ treatment or cell transplantation (compared with controls), increasing after $1 \mathrm{~d}$ by $6 \pm 1$ fold and $3 \pm 0.3$-fold, respectively, and remaining elevated at lower levels for $2 \mathrm{wk}$ (Fig. 1). This change was more pronounced in $\mathrm{CCl}_{4}$-treated rats. Also, hepatic expression of TNF- $\alpha$, macrophage inflammatory protein-2, monocyte chemotactic protein-1, and interferon-inducible protein-10 mRNAs increased within $6 \mathrm{~h}$ after $\mathrm{CCl}_{4}$ treatment or cell transplantation, as indicated by nonquantitative RT-PCR (not shown). Increased expression of TNF- $\alpha$ messenger RNA as a major mediator of the Kupffer cell response was verified by qPCR. For instance, after cell transplantation (compared with untreated controls) TNF- $\alpha$ expression increased significantly by $22 \pm 3$-fold, $56 \pm 1$-fold, $10 \pm 1$ fold, and $4 \pm 0.5$-fold at $6 \mathrm{~h}, 1 \mathrm{~d}, 3 \mathrm{~d}$, and $2 \mathrm{wk}$, respectively ( $P<0.05$, ANOVA with Holm-Sidak test).

These changes in Kupffer cell activation and cytokine expression were accompanied by the inhibition of $99 \mathrm{~m} \mathrm{Tc}$ mebrofenin excretion from the liver, such that more than $90 \%$ of Tpeak ${ }^{99 m}$ Tc-mebrofenin activity was retained $1 \mathrm{~d}$ after either $\mathrm{CCl}_{4}$ treatment or cell transplantation, compared

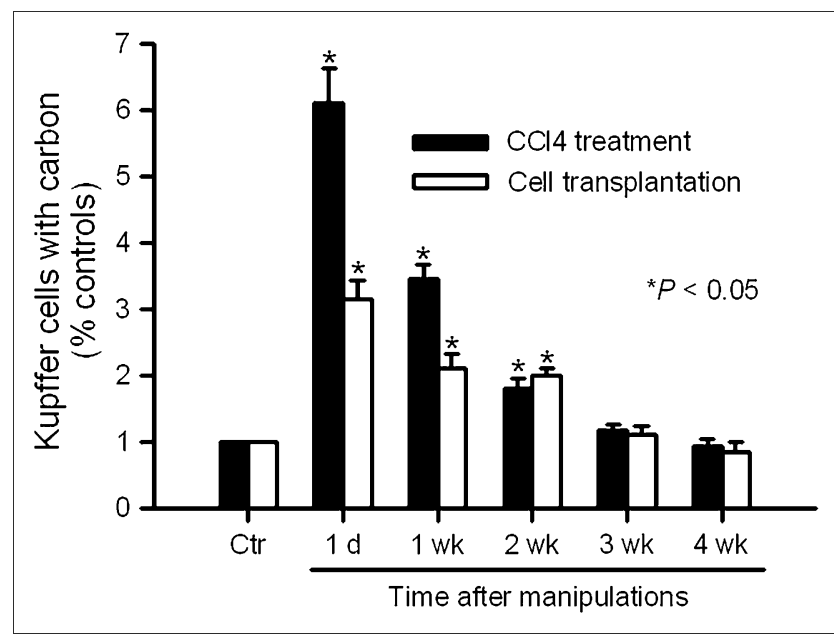

FIGURE 1. Changes in Kupffer cell activation. Shown is analysis of kinetics by which Kupffer cells were activated after $\mathrm{CCl}_{4}$ treatment or cell transplantation. Data indicated that Kupffer cells were activated more after $\mathrm{CCl}_{4}$ treatment than after cell transplantation. Asterisks indicate significant differences between normal controls and activated cells, although activated cells were present for long time after both $\mathrm{CCl}_{4}$ treatment and cell transplantation. Data were from multiple animals per time point $(n=3$ each). Ctr $=$ controls. 
with retention of less than $30 \%$ of ${ }^{99 \mathrm{~m}} \mathrm{Tc}$-mebrofenin activity in healthy control rats $(P<0.001, t$ test $)$. Previously, we reported that hepatic excretion of ${ }^{99 \mathrm{~m} T c-m e b r o f e n i n ~ w a s ~}$ impaired for $2 \mathrm{wk}$ after the administration of cells or $\mathrm{CCl}_{4}$ to animals only once $(8,9)$.

\section{Expression of Bile Canalicular Transporters Changed After Onset of Inflammation}

We considered that hepatic inflammation would alter expression of bile canalicular transporters because downregulation of hepatic transporters had previously been demonstrated in lipopolysaccharide-induced inflammation models of cholestasis in rats and mice (5). If there were a causal relationship between these 2 processes, this change should have occurred early and persisted during the period of abnormal ${ }^{99 \mathrm{~m}} \mathrm{Tc}-\mathrm{meb}$ rofenin excretion. qPCR assays showed significant changes in expression of $A b c b 4, A b c b 11$, and $\mathrm{Abcc} 2$ after $\mathrm{CCl}_{4}$ treatment or cell transplantation (Fig. 2). Compared with healthy controls, $6 \mathrm{~h}$ after $\mathrm{CCl}_{4}$ treatment expression decreased for $A b c b 4$ (38\% $\pm 0.6 \%)$,

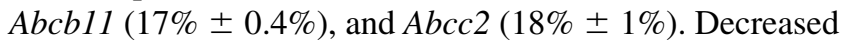
gene expression was also observed at $6 \mathrm{~h}$ after cell transplantation $(A b c b 4[13 \% \pm 4 \%], A b c b 11[16 \% \pm 3 \%]$, and Abcc2 [14\% $\pm 10 \%])(P<0.05$, ANOVA with HolmSidak test). After $4 \mathrm{wk}$, expression of $A b c b 4$ and $A b c b 11$ returned to normal or near-normal; $A b c c 2$ expression was still decreased to $44 \% \pm 1 \%$ in $\mathrm{CCl}_{4}$-treated animals and $66 \% \pm 15 \%$ in cell-transplanted animals $(P<0.05$, ANOVA with Holm-Sidak test). No consistent change was observed in Abcg2 gene expression (not shown).

We verified the findings at the protein level by Western blots and found that $A b c b 11$ protein level decreased shortly after either cell transplantation or $\mathrm{CCl}_{4}$ treatment, although the level returned to normal after $3 \mathrm{wk}$ (Fig. 3). The Abcc 2 protein level also decreased promptly after cell transplantation or $\mathrm{CCl}_{4}$ treatment. However, $\mathrm{Abcc} 2$ levels had not returned to normal even $4 \mathrm{wk}$ after $\mathrm{CCl}_{4}$ treatment. By contrast, expression of Slcolbl in the same tissue samples was unaffected by cell transplantation or $\mathrm{CCl}_{4}$ treatment. These findings were reproduced in samples from additional animals, and it was verified that inflammatory manipulations most prominently affected $A b c c 2$ expression.

\section{Role of Abcc2 in Hepatic Excretion of $99 \mathrm{~m}$ Tc-Mebrofenin}

We reasoned that if $A b c c 2$ were responsible for excreting ${ }^{99 m}$ Tc-mebrofenin, studies in the setting of an Abcc2-null phenotype would be helpful. Therefore, because the Abcc2 gene is naturally inactivated in HsdAmc:TR-Abcc 2 mutant rats $(10,11)$, we studied the capacity of the rats for excreting ${ }^{99 \mathrm{~m}} \mathrm{Tc}-\mathrm{meb}$ rofenin. First, to establish that the phenotype of these animals was correct, we measured total serum bilirubin, which should have been elevated. Serum bilirubin was $2.02 \pm 0.28 \mathrm{mg} / \mathrm{dL}$ in HsdAmc:TR-Abcc 2 mutant rats, compared with $0.23 \pm 0.05 \mathrm{mg} / \mathrm{dL}$ in healthy control HsdRccHan:WIST rats ( $n=6$ each) $(P=0.002$, MannWhitney rank sum test). Serum alanine aminotransferase and alkaline phosphatase levels were normal in both animal groups. Also, liver histology was normal in HsdAmc:TRAbcc2 mutant rats and HsdRccHan:WIST rats (Figs. 4A and 4B). Western blots showed absence of Abcc 2 protein in HsdAmc:TR-Abcc2 mutant rats. Abcb11 and Slcolbl proteins were expressed at normal levels in these animals. These findings verified the Abcc2-null state in HsdAmc:TR-Abcc2 rats and indicated that the animals were appropriate for our studies.

When HsdAmc:TR-Abcc2 mutant rats and their healthy counterpart rats were given ${ }^{99 \mathrm{~m}}$ Tc-mebrofenin $(n=6$ each), no differences were observed in Tpeak values,
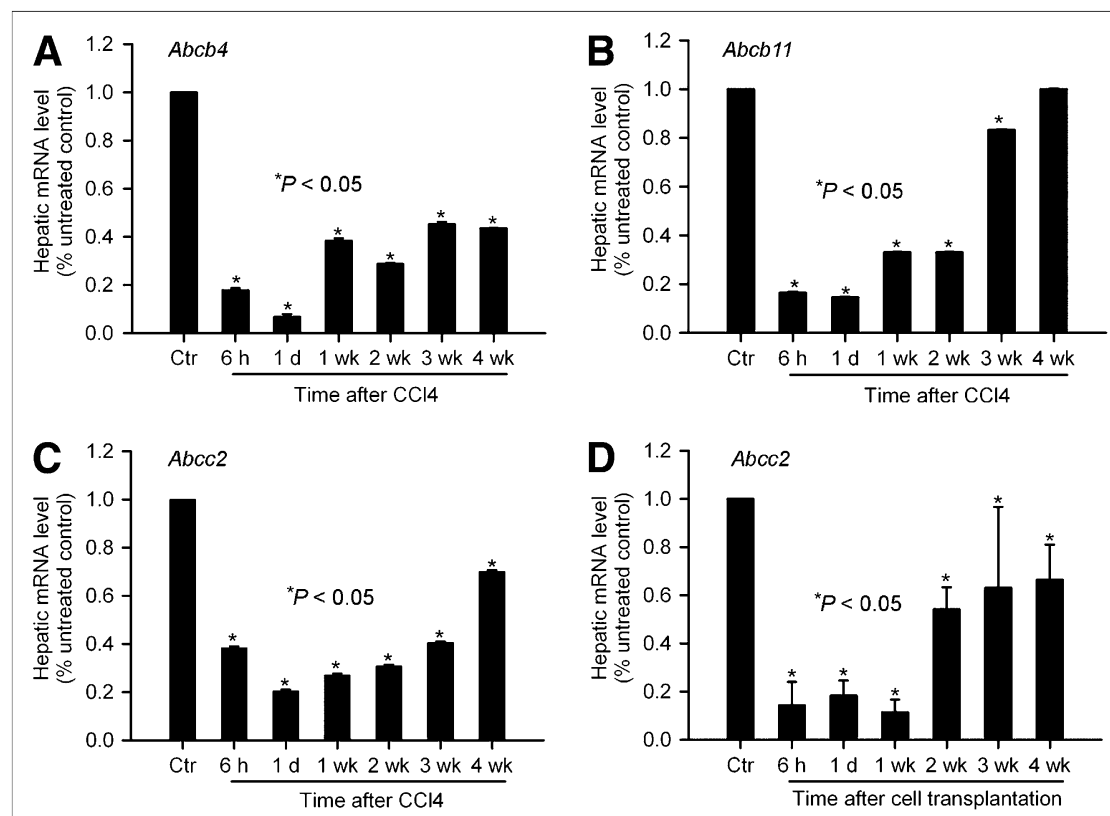

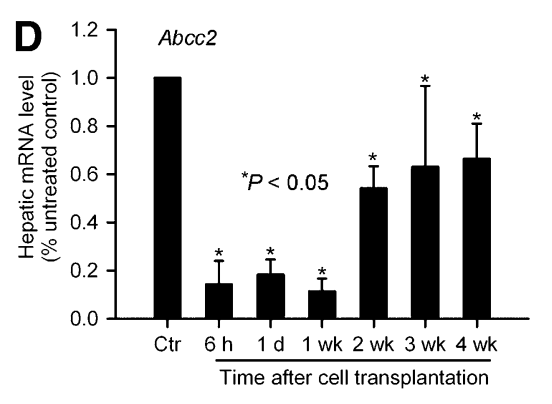

FIGURE 2. Perturbations in expression of canalicular transporters by hepatic inflammation. qPCR analysis of expression of $A b c b 4(\mathrm{~A}), A b c b 11$ (B), and $A b c c 2(C)$ genes from control rats and rats treated with $\mathrm{CCl}_{4}(\mathrm{~A}-\mathrm{C})$ or cell transplantation (D). After $\mathrm{CCl}_{4}$ treatment and cell transplantation, gene expression was promptly and persistently downregulated. Expression of Abcc2 gene was perturbed most profoundly, particularly in animals treated with $\mathrm{CCl}_{4}$. Subsequently, $\mathrm{Abcb11}$ expression showed earliest recovery, and $A b c c 2$ was expressed at subnormal levels through 4-wk period. Ctr $=$ controls. 
FIGURE 3. Changes in expression of canalicular proteins. Western blots are shown from same liver samples with stripping and reprobing of transblots. Expression of $A b c b 11$ declined initially $1 \mathrm{~d}$ and $1 \mathrm{wk}$ after $\mathrm{CCl}_{4}$ treatment (lanes 2 and 3 ) and returned to normal subsequently. Abcc2 expression also declined after $1 \mathrm{~d}$ but did not recover for the entire 4-wk duration of study. Expression of S/co1b1 was unaffected. Ctr $=$ controls.

indicating that the initial hepatic accumulation of ${ }^{99 \mathrm{~m}} \mathrm{Tc}-$ mebrofenin was unaltered (Fig. 5). However, hepatic excretion of ${ }^{99 \mathrm{~m}} \mathrm{Tc}-\mathrm{mebrofenin}$ was significantly different. Much of the ${ }^{99 \mathrm{~m}} \mathrm{Tc}-\mathrm{meb}$ rofenin activity at $60 \mathrm{~min}$ was retained in HsdAmc:TR-Abcc2 mutant rats $(73 \% \pm 5 \%)$, compared with healthy HsdRccHan:WIST rats $(22 \% \pm$ $3 \%)(P<0.001, t$ test $)$.

Because HsdAmc:TR-Abcc2 mutant rats did excrete a small fraction of ${ }^{99 \mathrm{~m}} \mathrm{Tc}-$ mebrofenin activity, we considered whether alternative pathways could have contributed to this result. In view of the simultaneous decline in $A b c c 2$ and Abcb11 expression after inflammatory perturbations, we examined whether drugs known to alter bile canalicular transporter activity could be helpful. Because cyclosporin A has been associated with the regulation of Abcbl1dependent and $A b c c 2$-dependent canalicular transport of bile salts and drugs $(13,15)$, we determined its effects on ${ }^{99 \mathrm{~m} T c-m e b r o f e n i n}$ excretion. When a 10 or $15 \mathrm{mg} / \mathrm{kg}$ dose of cyclosporin A was administered to healthy rats, accumulation of ${ }^{99 \mathrm{~m}} \mathrm{Tc}$-mebrofenin was not altered. However, more ${ }^{99 \mathrm{~m}} \mathrm{Tc}$-mebrofenin was retained in the liver, $70 \% \pm$ $6 \%$ and $77 \% \pm 4 \%$, respectively, of Tpeak values at 60 min, which was similar to the abnormality in HsdAmc:TRAbcc2 mutant rats (Fig. 6A). By contrast, in HsdAmc:TRAbcc2 mutant rats, excretion of ${ }^{99 \mathrm{~m}} \mathrm{Tc}-\mathrm{meb}$ rofenin was impaired from the outset, with a retention of $77 \% \pm 3 \%$ of Tpeak values at $60 \mathrm{~min}$, as before, and did not significantly change after the administration of cyclosporin A. Again, the accumulation of ${ }^{99 \mathrm{~m}} \mathrm{Tc}$-mebrofenin in animals treated with cyclosporin A was unchanged, indicating that excretion of ${ }^{99 m}$ Tc-mebrofenin was dependent most on $A b c c 2$ and that cyclosporin A most likely interfered with only this pathway of hepatic ${ }^{99 \mathrm{~m}} \mathrm{Tc}-\mathrm{mebrofenin}$ excretion.

\section{DISCUSSION}

These studies demonstrated that in experimental models of hepatic inflammation, excretion of ${ }^{99 \mathrm{~m}} \mathrm{Tc}-$ mebrofenin was impaired in the long term. Because the expression of bile canalicular transporters was also affected by hepatic inflammation, correlations could be made between ${ }^{99 \mathrm{~m}} \mathrm{Tc}-$ mebrofenin excretion and downregulated expression of

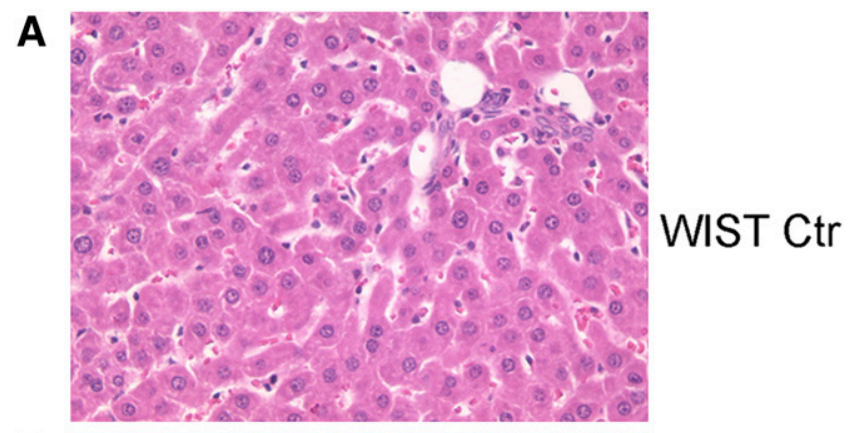

\section{B}
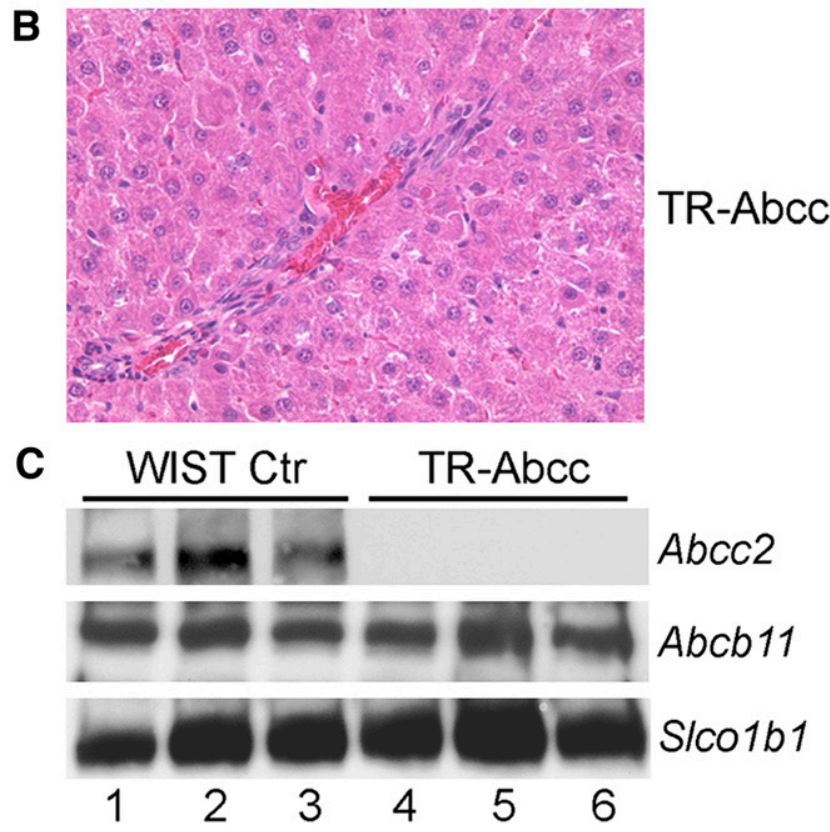

FIGURE 4. Phenotype of HsdRccHan:WIST rats (A) and HsdAmc:TR-Abcc2 mutant rats (B). Liver morphology was normal in these animals, with absence of inflammatory changes, biliary proliferation, or cholestasis. (C) Western blots of same samples for Abcc2, which was present in HsdRccHan:WIST rats (lanes 1-3) and absent in HsdAmc:TR-Abcc2 mutant rats (lanes 4-6) and for Abcb11 and S/co1b1, which were expressed normally. Each lane represents liver from different animal. Ctr = controls. (Original magnification in $A$ and $B, \times 200$; hematoxylin and eosin stain.)

specific transporters to incriminate $A b c c 2$ as the likely ${ }^{99 \mathrm{~m} T c-m e b r o f e n i n}$ transporter. This correlation was directly established in HsdAmc:TR-Abcc2 mutant rats, which constituted an excellent model of $A b c c 2$ deficiency $(10,11)$. Further studies in animals treated with cyclosporin A verified that $A b c c 2$ was responsible for most ${ }^{99 \mathrm{~m} T c-m e b r o f e n i n}$ excretion. These findings indicated that as a ligand for

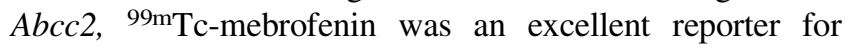
demonstrating the integrity of this cellular pathway, which will be significant for interpreting abnormalities in ${ }^{99 \mathrm{~m} T c-}$ mebrofenin imaging and for developing new applications with ${ }^{99 \mathrm{~m} T c-m e b r o f e n i n}$ or related analogs. 


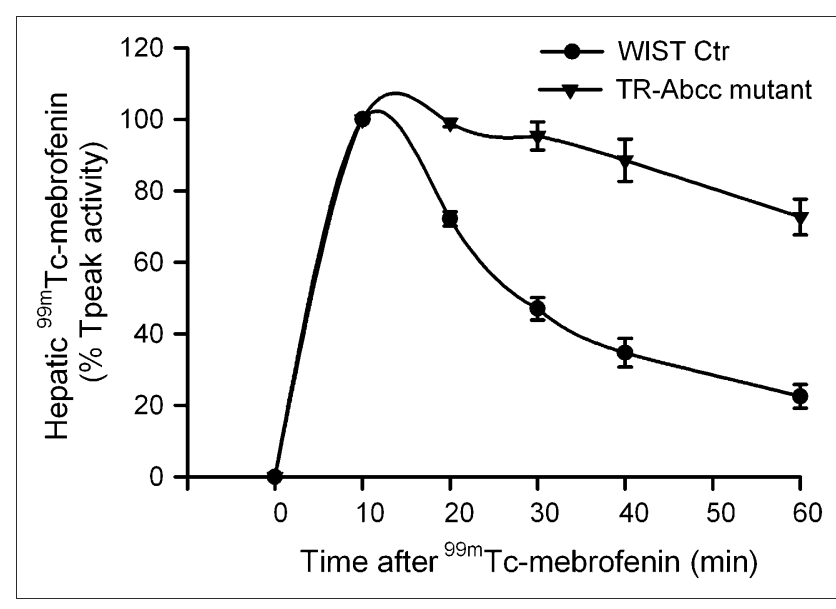

FIGURE 5. Scintigraphy showing impaired hepatic excretion of $99 \mathrm{mTc}$-mebrofenin. Time-activity curves from healthy control HsdRccHan:WIST rats and HsdAmc:TR-Abcc2 mutant rats ( $n=6$ each). Initial accumulation of ${ }^{99 m}$ Tcmebrofenin was similar in both groups. However, 99mTcmebrofenin was promptly excreted in control rats, whereas its excretion was markedly impaired in HsdAmc:TR-Abcc2 mutant rats, resulting in retention of $22 \% \pm 3 \%$ vs. $73 \% \pm$ $5 \%$ of the Tpeak activity at $60 \mathrm{~min}(P<0.001, t$ test). Ctr $=$ controls.

The mechanism by which ${ }^{99 \mathrm{~m}} \mathrm{Tc}$-mebrofenin is incorporated in hepatocytes is not fully defined, although the uptake process is thought to be sodium-independent, without requiring the Slcolal gene, which should be expressed on the sinusoidal domain of hepatocytes (3). However, alternative sinusoidal transporters (i.e., Slcolbl and Slcolb3) did allow ${ }^{99 m}$ Tc-mebrofenin uptake to otherwise nonpermissive Xenopus oocytes. We found that expression of Slcolb1 was unaffected by hepatic inflammation in rats, as was in agreement with normal initial hepatic accumulation of ${ }^{99 \mathrm{~m}} \mathrm{Tc}-$ mebrofenin, indicated by Tpeak values under conditions studied here and as discussed in detail previously (8). Similarly, fractional retention of peak hepatic ${ }^{99 \mathrm{~m} T c}$-mebrofenin over $60 \mathrm{~min}$ was established as an effective parameter for assessing ${ }^{99 \mathrm{~m} T c-m e b r o f e n i n ~ e x c r e-~}$ tion, and this excretion was rapidly and persistently inhibited by hepatic inflammation due to cytokines, such as interleukin-6 and TNF- $\alpha$ (8), which are major mediators of phagocyte and macrophage responses. Here, we found that multiple cytokines were activated by inflammatory perturbations, including significant and prolonged activation of TNF- $\alpha$. In agreement with our findings, inflammatory cytokines downregulated the expression of bile canalicular transporters in the short term, including $A b c c 2, A b c b 11$, and other genes (16-18), although not Slcolbl (19). Here, we found that downregulation of canalicular transporters can continue in the long term during ongoing activation of inflammatory cells and local release of relevant cytokines. The role of nuclear receptor-based signaling in regulating bile canalicular transporter expression under various exper-

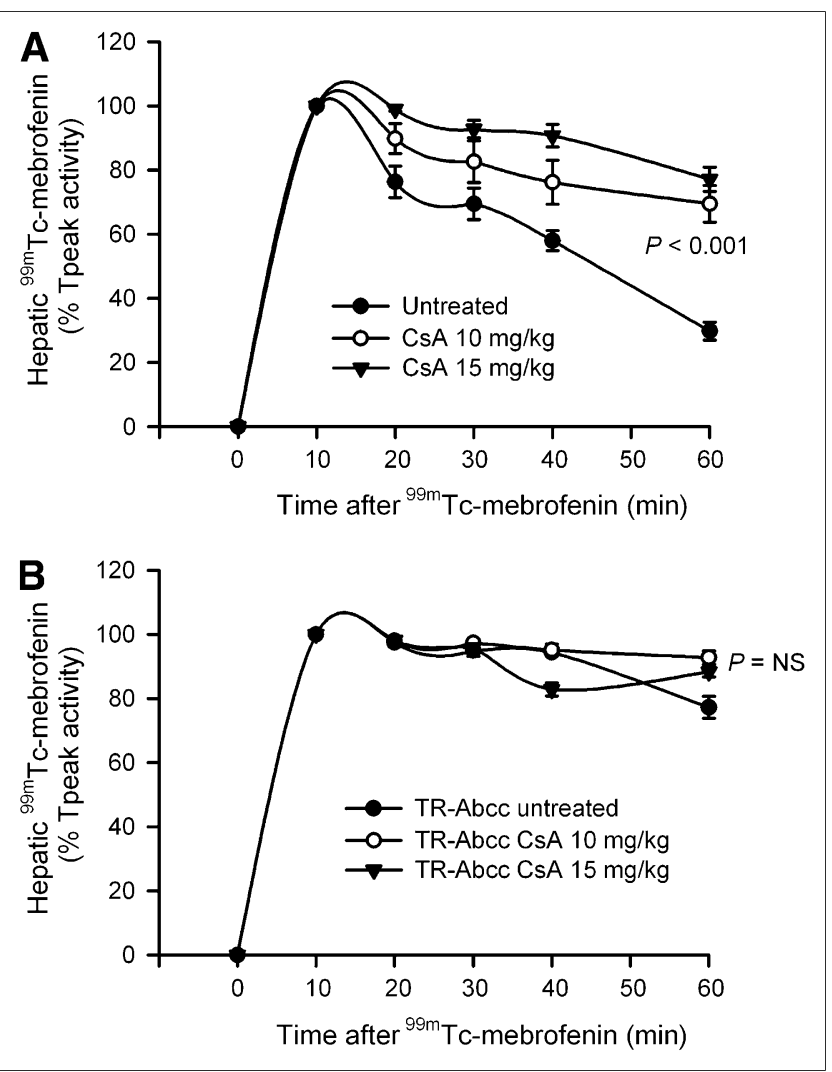

FIGURE 6. Regulation of hepatic 99mTc-mebrofenin excretion by cyclosporin A. (A) Time-activity curves in healthy F344 rats with and without prior administration of cyclosporin A ( $n=6$ each). In these animals, initial accumulation of $99 \mathrm{~m}$ Tc-mebrofenin was unchanged. However, ${ }^{99 m}$ Tcmebrofenin excretion was impaired with retention of $70 \% \pm$ $6 \%$ and $77 \% \pm 4 \%$ of the Tpeak activity at $60 \mathrm{~min}$ in recipients of 10 and $15 \mathrm{mg} / \mathrm{kg}$ doses of cyclosporin $A$ (compared with only $30 \% \pm 3 \%$ in control animals), respectively ( $P<0.001$, ANOVA). (B) Changes in ${ }^{99 m}$ Tc-mebrofenin excretion in HsdAmc:TR-Abcc2 mutant rats with or without cyclosporin A ( $n=6$ each). In these animals, 99mTcmebrofenin excretion was already impaired and cyclosporin A did not cause further significant impairment. CsA = cyclosporin A; NS = not significant, ANOVA.

imental conditions and disease states has also been established (5). Therefore, the assessment of hepatobiliary transport with noninvasive ${ }^{99 \mathrm{~m}} \mathrm{Tc}$-mebrofenin imaging will be effective for further biologic and clinical studies of $A b c c 2$ regulation.

The transport abnormalities in HsdAmc:TR-Abcc2 mutant rats have been characterized previously (11). These rats constitute an authentic model of Dubin-Johnson syndrome in people, in whom the $A b c c 2$ gene is mutated (10), except that the liver in Dubin-Johnson syndrome is characterized by an accumulation of a dark pigment and lipofuscin, which was not observed in the liver of HsdAmc:TR-Abcc2 mutant rats. Our finding of ${ }^{99 \mathrm{~m}} \mathrm{Tc}-$-mebrofenin retention in HsdAmc:TR-Abcc2 mutant rats indicated clearly that 
Abcc2 was required for transporting much of the ${ }^{99 \mathrm{~m}} \mathrm{Tc}-$ mebrofenin into bile. This correlated with long-standing observations in Dubin-Johnson syndrome of abnormal handling of ${ }^{99 \mathrm{~m}} \mathrm{Tc}-\mathrm{mebrofenin}$ analogs with hepatic accumulation and inability to clear radiotracers over time (20). These findings established that ${ }^{99 \mathrm{~m}} \mathrm{Tc}-\mathrm{mebrofenin}$ imaging will provide a specific diagnostic test for Dubin-Johnson syndrome and for other disorders characterized by the loss of $A b c c 2$ activity. Moreover, our studies with cyclosporin A demonstrated that pharmacologic interactions involving $A b c c 2$ can be studied in intact animals by ${ }^{99 \mathrm{~m}} \mathrm{Tc}$-mebrofenin assays. Excretion of ${ }^{99 \mathrm{~m}} \mathrm{Tc}$-mebrofenin is not affected by elevated levels of serum bilirubin (2), which constitutes another substrate of $A b c c 2$ (21), suggesting that $A b c c 2$ likely has greater affinity for ${ }^{99 \mathrm{~m} T c-m e b r o f e n i n ~ t h a n ~ f o r ~}$ bilirubin. On the other hand, increased retention of ${ }^{99 \mathrm{~m}} \mathrm{Tc}-$ mebrofenin after treatment of animals with cyclosporin A indicated that this drug could more preferentially bind $A b c c 2$. The excretion of some ${ }^{99 \mathrm{~m}} \mathrm{Tc}-$ mebrofenin activity in HsdAmc:TR-Abcc2 mutant rats suggested that pathways other than $A b c c 2$ might play smaller additional roles. In Dubin-Johnson syndrome, compensatory upregulation of the $A b c c 3$ gene at the lateral membrane of hepatocytes could result in reflux of conjugated bilirubin into the blood (11), although the $A b c c 3$ gene was not upregulated in $A b c c 2$ knockout mice (21), raising doubts about that alternative for ${ }^{99 \mathrm{~m}} \mathrm{Tc}$-mebrofenin removal. However, increased expression of $A b c c 3$ and some other transporters capable of excreting substrates into other locations, for example, the gastrointestinal tract (11), is not excluded. Also, the possibility that additional bile canalicular transporters (e.g., $A b c b 4$ ) could excrete small amounts of ${ }^{99 \mathrm{~m} T c-m e b r o f e n i n}$ is not excluded. $A b c b 4$ has a similar minor role in excreting sestamibi (largely excreted by the Abcbl protein (22)); however, liver injury and inflammation in mutant mice lacking $A b c b 4$ might produce confounding data in demonstrating this possible minor role of $A b c b 4$ in ${ }^{99 \mathrm{~m}} \mathrm{Tc}-$ mebrofenin excretion.

Taken together, our findings indicate that the identification of perturbations in molecular pathways represented by the $A b c c 2$ gene through assays of ${ }^{99 \mathrm{~m}} \mathrm{Tc}-\mathrm{mebrofenin}$ will provide further ways to approach a variety of physiologic, pathobiologic, and pharmacologic mechanisms.

\section{CONCLUSION}

Studies in animal models demonstrated that ${ }^{99 \mathrm{~m} T c-}$ mebrofenin was largely excreted by Abcc2-mediated hepatobiliary transport. This mechanism should guide analysis of pathophysiologic perturbations in the hepatic handling of ${ }^{99 \mathrm{~m} T c-m e b r o f e n i n}$ and diagnosis of impairments in $A b c c 2$ gene function.

\section{ACKNOWLEDGMENTS}

We thank Chaoying Zhang for contributing technical assistance. This work was supported in part by National
Institutes of Health grants R01 DK46952, P30 DK41296, P30 CA13330, M01 RR12248, and R37 HD20362.

\section{REFERENCES}

1. Krishnamurthy GT, Krishnamurthy S. Cholescintigraphic measurement of liver function: how is it different from other methods? Eur J Nucl Med Mol Imaging. 2006;33:1103-1106.

2. Nunn AD, Loberg MD, Conley RA. A structure-distribution-relationship approach leading to the development of Tc-99m mebrofenin: an improved cholescintigraphic agent. J Nucl Med. 1983;24:423-430.

3. Ghibellini G, Leslie EM, Pollack GM, Brouwer KL. Use of Tc-99m mebrofenin as a clinical probe to assess altered hepatobiliary transport: integration of in vitro, pharmacokinetic modeling, and simulation studies. Pharm Res. 2008; 25:1851-1860.

4. Planchamp C, Hadengue A, Stieger B, et al. Function of both sinusoidal and canalicular transporters controls the concentration of organic anions within hepatocytes. Mol Pharmacol. 2007;71:1089-1097.

5. Kosters A, Karpen SJ. Bile acid transporters in health and disease. Xenobiotica. 2008;38:1043-1071.

6. Bochkis IM, Rubins NE, White P, Furth EE, Friedman JR, Kaestner KH. Hepatocyte-specific ablation of Foxa2 alters bile acid homeostasis and results in endoplasmic reticulum stress. Nat Med. 2008;14:828-836.

7. Strautnieks SS, Byrne JA, Pawlikowska L, et al. Severe bile salt export pump deficiency: 82 different ABCB11 mutations in 109 families. Gastroenterology. 2008;134:1203-1214.

8. Joseph B, Bhargava KK, Tronco GG, Palestro CJ, Gupta S. Systemic and local release of inflammatory cytokines regulates hepatobiliary excretion of ${ }^{99 \mathrm{~m}} \mathrm{Tc}$ mebrofenin. Nucl Med Commun. 2008;29:336-344.

9. Joseph B, Bhargava KK, Tronco GG, Palestro CJ, Gupta S. Molecular pathwayspecific ${ }^{99 \mathrm{~m}} \mathrm{Tc}-\mathrm{N}$-(3-bromo-2,4,6-trimethyacetanilide) iminodiacetic acid liver imaging to assess innate immune responses induced by cell transplantation. Nucl Med Commun. 2009;30:126-133.

10. Paulusma CC, Kool M, Bosma PJ, et al. A mutation in the human canalicular multispecific organic anion transporter gene causes the Dubin-Johnson syndrome. Hepatology. 1997;25:1539-1542.

11. Johnson BM, Zhang P, Schuetz JD, Brouwer KL. Characterization of transport protein expression in multidrug resistance-associated protein (Mrp) 2-deficient rats. Drug Metab Dispos. 2006;34:556-562.

12. Joseph B, Malhi H, Bhargava KK, Palestro CJ, McCuskey RS, Gupta S. Kupffer cells participate in early clearance of syngeneic hepatocytes transplanted in the rat liver. Gastroenterology. 2002;123:1677-1685.

13. Funk C, Ponelle C, Scheuermann G, Pantze M. Cholestatic potential of troglitazone as a possible factor contributing to troglitazone-induced hepatotoxicity: in vivo and in vitro interaction at the canalicular bile salt export pump (Bsep) in the rat. Mol Pharmacol. 2001;59:627-635.

14. Wu YM, Joseph B, Gupta S. Immunosuppression using the mTOR inhibition mechanism affects replacement of the rat liver with transplanted cells. Hepatology. 2006;44:410-419.

15. Hesselink DA, van Hest RM, Mathot RA, et al. Cyclosporine interacts with mycophenolic acid by inhibiting the multidrug resistance-associated protein 2 . Am J Transplant. 2005;5:987-994.

16. Hartmann G, Cheung AK, Piquette-Miller M. Inflammatory cytokines, but not bile acids, regulate expression of murine hepatic anion transporters in endotoxemia. J Pharmacol Exp Ther. 2002;303:273-281.

17. Geier A, Dietrich CG, Voigt S, et al. Cytokine-dependent regulation of hepatic organic anion transporter gene transactivators in mouse liver. Am J Physiol Gastrointest Liver Physiol. 2005;289:G831-G841.

18. Siewert E, Dietrich CG, Lammert F, et al. Interleukin-6 regulates hepatic transporters during acute-phase response. Biochem Biophys Res Commun. 2004;322:232-238.

19. Geier A, Dietrich CG, Trauner M, Gartung C. Extrahepatic cholestasis downregulates Oatp1 by TNF- $\alpha$ signalling without affecting Oatp2 and Oatp4 expression and sodium-independent bile salt uptake in rat liver. Liver Int. 2007;27:1056-1065.

20. Bar-Meir S, Baron J, Seligson U, Gottesfeld F, Levy R, Gilat T. ${ }^{99 m}$ Tc-HIDA cholescintigraphy in Dubin-Johnson and Rotor syndromes. Radiology. 1982; 142:743-746.

21. Chu XY, Strauss JR, Mariano MA, et al. Characterization of mice lacking the multidrug resistance protein MRP2 (ABCC2). J Pharmacol Exp Ther. 2006; 317:579-589.

22. Joseph B, Bhargava KK, Malhi H, et al. Sestamibi is a substrate for MDR1 and MDR2 P-glycoprotein genes. Eur J Nucl Med. 2003;30:1024-1031. 